\title{
Coinfection dengue and melioidosis infection
}

\section{Coinfecção de dengue e melioidose}

\section{Viroj Wiwanitkit ${ }^{[1,[2]}$}

[1]. Wiwanitkit House, Bangkhae, Bangkok, Thailand. [2]. Medical University, Joseph Ayobabalola University, Nigeria.

\section{Dear Editor,}

The recent publication on severe coinfection of melioidosis and dengue fever in Brazil is very interesting ${ }^{1}$. Macedo et al. noted for the need to consider melioidosis among the reported differential diagnoses of community-acquired infections where both melioidosis and dengue fever are endemic ${ }^{1}$. Indeed, the concurrent infection between two tropical diseases in endemic area can be expected. For melioiodis and dengue, the concurrent is already reported in Thailand ${ }^{2}$ as noted by Macedo et al. ${ }^{1}$. There are some remained interesting questions to be further studied. The exact prevalent rate of concurrent dengue and melioidosis infection should be systematically studied. The rarity, very few reports, might be due to several factors such as: a) under-report; b) under-diagnosis; c) no actual concurrent infection. Indeed, the concurrent infection can be seen only if: a) there are both pathogens at the same time and same place; $b$ ) there must be the vector for transmission of dengue; $c$ ) the host has to expose to both diseases. However, where there is any interaction between the two pathogens that might promote or prevent concurrent infection is another interest question.

\section{REFERENCES}

1. Macedo RN, Rocha FA, Rolim DB, Vilar DC, Araújo FM, Vieira NN, et al. Severe coinfection of melioidosis and dengue fever in Northeastern Brazil: first case report. Rev Soc Bras Med Trop 2012; 45:132-133.

2. Pongrithsukda V, Simakachorn N, Pimda J. Childhood melioidosis in northeastern Thailand. Southeast Asian J Trop Med Public Health 1988; 19:309-316.

Address to: Dr. Viroj Wiwanitkit. Wiwanitkit House, Bangkhae, 10160 Bangkok Thailand. Phone: 668 7097-0933

e-mail: somsriwiwan@hotmail.com; wviroj@yahoo.com

Received in 24/05/2012

Accepted in 20/06/2012

\section{Authors reply: Coinfection dengue and melioidosis infection}

\author{
Resposta dos autores: Coinfecção de \\ dengue e melioidose
}

\section{Dionne Bezerra Rolim ${ }^{[1]}$ and Luciano Pamplona de Góes Cavalcanti ${ }^{[2], ~[3] ~}$}

[1]. Curso de Medicina, Universidade de Fortaleza, Fortaleza, CE. [2]. Departamento de Saúde Comunitária, Faculdade de Medicina, Universidade Federal do Ceará, Fortaleza, CE. [3]. Faculdade de Medicina, Faculdade Christus, Fortaleza, CE.

\section{Dear Sir,}

The considerations presented by Viroj Wiwanitkit are extremely important and relevant. The objective of our study was to report the first case of co-infection with melioidosis and severe dengue that occurred in northeastern Brazil ${ }^{1}$. Dengue was first diagnosed in Ceará in 1986 and has since become highly endemic, with frequent epidemics and high mortality rates ${ }^{2-4}$. Melioidosis was first diagnosed in $2003^{5,6}$, and the first sero-epidemiological study to determine the disease occurrence was performed only recently and in only two municipalities ${ }^{7}$.

We agree with the Viroj Wiwanitkit statement that the rarity of such reports may be due to underreporting and/or underdiagnosis. However, this possibility appears to be more frequent for cases of melioidosis because it is a complicated disease to diagnose and has only recently been described in Brazil ${ }^{5}$. Similar underreporting, but without co-infection, was suggested by Lima et al. when they detected cases of hantavirus among suspected dengue patients for the first time ${ }^{8}$.

As the author himself stated, there is the potential for a simultaneous infection given that, in Ceará, northeastern Brazil, Aedes aegypti is present, the four previously isolated dengue virus serotypes are in circulation, and the bacterium Burkolderia pseudomallei is present in the soil and water ${ }^{9}$. Together, these factors favor the possibility that other similar cases of co-infection may occur.

Thus, the interaction between these two pathogens merits consideration, particularly because both diseases involve the host's immune response, which is certainly one aspect that requires further studies. 


\section{REFERENCES}

1. Macedo RN, Rocha FA, Rolim DB, Vilar DCLF, Araújo FMC, Vieira NN, et al. Severe coinfection of melioidosis and dengue fever in Northeastern Brazil: first case report. Rev Soc Bras Med Trop 2012; 45:132-133.

2. Vasconcelos PFC, Menezes DB, Melo LP, Pessoa ETFP, Rodrigues SG, Rosa EST, et al. A Large epidemic of dengue fever with dengue hemorragic cases in Ceará State, Brazil, 1994. Rev Inst Med Trop São Paulo 1995; 37:253-255.

3. Cavalcanti LPG, Coelho ICB, Vilar DCLF, Holanda SGS, Escóssia KN, Souza-Santos R. Clinical and epidemiological characterization of dengue hemorrhagic fever cases in northeastern, Brazil. Rev Soc Bras Med Trop 2010; 43:355-358.

4. Cavalcanti LP, Vilar D, Souza-Santos R, Teixeira MG. Change in Age Pattern of Persons with Dengue, Northeastern Brazil. Emerg Infect Dis 2011; 17:132-134.
5. Miralles IS, Maciel MCA, Angelo MRF, Gondini MM, Frota LHF, Reis CMF, et al. Burkholderia pseudomallei: a case report of a human infection in Ceará, Brazil. Rev Inst Med Trop Sao Paulo 2004; 46:51-54.

6. Rolim DB, Vilar DCLF, Sousa AQ, Miralles IS, Oliveira DCA, Harnett G, et al. Melioidosis, Northeastern Brazil. Emerg Infect Dis 2005; 11:1458-1460.

7. Rolim DB, Vilar DCLF, Cavalcanti LPG, Freitas LBN, Inglis TJJ, Rodrigues JLN, et al. Burkholderia pseudomallei Antibodies in Individuals Living in Endemic Regions in Northeastern Brazil. Am J Trop Med Hyg 2011; 84:302-305.

8. Lima DM, Sabino-Santos Jr G, Oliveira ACA, Fontes RM, Colares JKB, Araúno FMC, et al. Hantavirus infection in suspected dengue cases from State of Ceará, Brazil. Rev Soc Bras Med Trop 2011; 44:795-796.

9. Rolim DB, Rocha MFG, Bilhante RSN, Cordeiro RA, Leitão-Junior NP, Inglis TJJ, et al. Environmental Isolates of Burkholderia pseudomallei in Ceará State, Northeastern Brazil. Appl Environ Microbiol 2009; 75:1215-1218. 